\title{
GLOBALIZATION AND CULTURAL ALIENATION OF STUDENTS OF TERTIARY INSTITUTION IN CROSS RIVER STATE
}

\author{
TANDU MARY ANYIE (Ph.D) ${ }^{\mathrm{a}}$ OGAR VERONICA JOHN ${ }^{\mathrm{b}} *$ \\ a maryanyie@gmail.com \\ Cross River State College of Education Akamkpa, Department of Social Science Education, Calabar: 500001, Nigeria \\ Cross River State College of Education Akamkpa, Department of Social Science Education, Calabar: 500001, Nigeria
}

\begin{abstract}
This research work directs attention to how overriding influence of the new global culture has caused students of our tertiary institutions in the state to change their behaviour and attitudinal orientations. The problem identification derived from an observed change in students teachers relationship which was manifest in an aspect of non- recognition of lecturers that were not teaching them. The research was therefore primarily contemplated based on the need to investigate whether overall behavioural mode were influenced by what. and what. Thus, the objective/ purpose was to evaluate the co-connection between the new global culture and their cultural discembeddedness. Using a multistage sampling technique the subject were eventually isolate into two groups. In the basis of gender and two hypothesis were formulated for the purpose of statistical analysis. The chi-square $\left(\mathrm{x}^{2}\right)$ technique was used in analysis both hypotheses. The results showed that the null hypotheses were rejected while the alternatives were accepted. Indicating that globalization has significant influence on students cultural orientation. Our conclusion directs attention to the point that efforts should be made by the holders in education to educate the youths on the danger of abandoning one's own cultural identity,
\end{abstract}

Keyword: Globalization, Cultural Allienation, Tertiary Institution

\subsection{Executive summary}

This research work is conjectured based on the recognition of the sprawling societal change in demographic, cultural, political, economic and other spheres of human endeavours caused by the ensuing phenomenon of globalization.

In all circles globalization has been viewed to cause erosion of existing systems in all human affairs. In 
the particular instance of this research endeavour, cultural diversity has been threatened leading to the apprehension that if the spate of culture diffusion continuous in the same way it might lead to the production of a universal global cultural or homogenous culture. Hence, the problem of the research directs attention to how this trend is manifesting in Tertiary Institutions in Cross River State, Nigeria.

Prior to this period, colonial incursion has caused the abrasion of most traditional cultural values. Added to the impetus of the globalization process, the tendency might be that all ingrained vestiges of our innate identities might be swarmed in the aggressive wave of globalization phenomena.

Fundamentally, the objective of this research is to isolate the parameters of gender susceptibility or resistance to the wave of globalization incursion. The research subjects used were students of tertiary institutions in the state, Cross River, Nigeria. Sampling was based on purposive and stratified techniques. Two hundred subjects were used drawn from two tertiary institutions. Data was collected using the questionnaire as an instrument for eliciting responses. Analysis was based on the statistical technique of chisquare The results of the findings were as follows; that there is a significant difference in the male and female students orientation toward the new globalization culture.

\subsection{Introduction}

Since its creation, the world has constantly changed over time. At its primordial stage, the change was slow and spontaneous due to inadequate knowledge of science and technology and overall environmental systems thinking. Hence the primitive man existed and survived by trial and error. The early cradle of civilization in Egypt, Mesopotarnia and other later empires witnessed the emergence of scientific speculators concerned with the origin of the universe as evidenced by the contributions of the Miletian scholars led by Thales (624 530BC). The industrial revolution which started in Britain in the 17th century (1650 AD) launched the world into a new phase of change that caused a colossal appreciation of the knowledge of the world bringing about a stage of global integration. This trend began the fundamental starting point of globalization or modernization, which was characterized by several spates of explosive revolutions especially at the later stage of the 20th Century, Important subsets of these revolutions were scientific revolution, transport revolution, revolution in information and communication technology and urban intensification. Today, the purveyors of this revolutions namely Britain, Germany, Scandinavia, the Netherlands, USA/Canada and others have arrived at the stage of post industrial transformation with large scale change in the economic and technological change in geographic space.

This is seen by high technology development (ICT), sprawling urbanization characterized by centrifugal urban intensification rather than centripetal. In its spatial parlance this phase is witnessing development of conurbations' and megalopolis. As a whole the achievements of supersonic/high speed transportation coupled with the ICT network have caused the achievement of "time space economy" where distance is no more a barrier. This is rather called global integration. The world is said to be global village due to the high levels of interconnectivity. Viewed as a whole this change has the bright and dark side of it on all life spheres including cultural cohesion of a people.

\subsection{Statement of the problem}

At face value every change may be greeted with laudible applause but there is always a dark side of every golden situation. In particular, globalization or modernization is antithetical in that its mode of integration carries with it corresponding ambit of disintegration or spoilage. From the environmental stand 
point, globalization is solely responsible for the widespread environmental dereliction or deterioration in the form of resource over exploitation, climate change, pollution in all its form and so on.

Socially, it has caused wide-spread dislocation of traditional systems and annihilation of cultures. Enduring prevalence of skirmishes at, local, regional and national level all predicate on wide spread development of armaments of all kinds.

The focus of this research work is on underscoring the relation between globalization and cultural alienation of students of Tertiary Institutions in Cross River State. The institutions refer to the colleges of Education, Universities and Polytechnics. It is focussed on how indoctrination has led to dependency thinking by some of the subjects and the degree to which this orientation has affected them.

Anih (2007) in his analysis of his subject of "Authentic education for the third Millennium Nigeria" highlighted the basis for inappropriate "acculturation" and "enculturation". "Our learning system did not prepare the learner for creative thinking and critical reasoning as such, the learners he said, is not provided the cognitive perspective of thinking for himself or engaging in analytic/synthetic reasoning".

Thus, our knowledge is not assimilated knowledge but imbibed knowledge. This means information is swallowed "hook-line-and-sinker" without sifting. This provides the basis for cultural alienation. Hence, the gap to be filled here basically is an appreciation of how these subjects view themselves in the context of their culture and also investigate if they could be reversal in thinking in appropriate direction. Following the above programme and the practical manifestation of the impact of cultural annihilation of our educated youths there is urgent need to tackle this ugly trend headlong. Imperative for this research is borne out of the need to correct the existing anomalies. Educational policy planning at all levels needs this work in order to orient the education programme with the changing world scenario.

\subsection{Purpose and objectives of the research} Purpose of the study

The broad view aim of this study is on the evaluation how cultural embeddedness of students of tertiary institution in Cross River State have been influenced by elements of globalization.

\section{Objective of the study}

Deriving from the broad view aim above, the following specific objectives are herein stated:

- To examine the influence of globalization on male students cultural orientation in their institution of learning.

- To examine the influence of globalization on female students cultural orientation in the study area.

\subsection{Justification for the research}

Acculturation, or enculturation as the anthropologist may coin it, have far reaching implications for the coalescing cultures. An understanding of actual direction of change may be useful guide for creating a reversal in the direction of cultural blending or intercultural accretion. A system where one culture, completely annihilate the elements of other cultures is antithetical to appropriate societal evolution. Results or findings from research such as this will provide a basis for creation of intercultural learning which will give clear insights into the different modes of cultural borrowing and/or assimilation. Cultural disembeddedness or enculturation is a dangerous trend which produces a state of cultural anomie or loss of identity. Intercultural education or learning borders on recognition of diversity among persons. The actual proclamation of this 
thesis finds inspiration on the need to carter for human rights and the rights of minorities and migrants based the Geneva Convention on asylum....against discrimination, race and racism.

Following the above programme and the practical manifestation of the impact of cultural annihilation of our educated youths there is urgent need to tackle this ugly trend headlong. This provides the imperative for this research in order that the existing anomalies will be corrected.

\subsection{Study scope}

The geographical scope of study shall be the entire tertiary institutions, which are spread through in the three senatorial districts namely North, Central and Southern senatorial districts. The subject matter scope shall be limited to investigate impact of globalization on the worldview of students of tertiary institutions in the state (Cross River).

\subsection{Research hypothesis}

\section{Hypothesis I}

H0: Globalization has no significant impact on male student's cultural orientation tertiary institutions in Cross River State, Nigeria.

HI: Globalization has a significant impact on male student's cultural orientation in tertiary institution in Cross River State, Nigeria.

\section{Hypothesis II}

H0: Globalization has no significant impact on female student's cultural orientation in tertiary institutions in Cross River State.

HI: Globalization has a significant impact on male student's cultural orientation in tertiary institutions in Cross River State, Nigeria.

\subsection{Literature review}

\section{An over view}

Globalization and modernization have synonymous connections, while modernization has to do with progressive change in human development from different perspective or forms; globalization is the sprawling, borderless expansion of development or rather modernization. In other words, globalization is full-blown modernization leading to global linkage or interconnectivity (Watson 2000). Prodigious definition or explanation of globalization has been provided in the literature from different authorities in the field.

The oxford Advanced Learner Dictionary (2001) explained that Globalization is the act globalizing, deriving from the noun: "Global" meaning worldwide or universal. Similarly the international forum for Globalization (IFG: 2006) view globalization as the present worldwide drive towards a globalized economic system dominated by supranational cooperate trade and banking institutions, that are not accountable to democratic processes or national Governments. This definition tends to suggest that globalization has the potential of weakening the sovereignty of nation states. Again the World Bank publication of 2006 noted that globalization is the growing integration of economies and society around the world

Appebaum and Robinson (2000) explained that globalization is the process of reshaping how we have traditionally gone about studying the social world and human culture---. This definition directly addresses the 
true essence of the objective of this study which centers on cultural alienation of students /youths in tertiary institutions in Cross River State. Furthermore, the united Nations Poverty and Development Division (1999) held that globalization generally refers to increasing interactions across National boundaries that affect many aspects of life including education, economies, social life, culture and politics.

\subsection{Acculturation or Cultural Disembebedness}

The essence of acculturation, cultural disembedness has been a subject of vigorous inquiry among cultural anthropologists. This impetus is predicative on the feeling by this practitioners that acculturation or loss of minority culture through domination by the majority culture represents the irrepressible loss of humanity's heritage and diversity (Harrison 2001), Boyd and Richardson 1994. This expression chearly addresses the problem statement of the research work.

Doyens of cultural anthropology such as that by Harner (2001) who spoke of the Jivari society of Brazil as one of the few culture in history of the world that have been so disintegrated by simple introduction of centralized law at and order have rendered similar phrases. He went further to state that "the traditional culture and society of the Jivari are on the wane. Siskind (2005) in his study of the scaranuau people of Peru said she was stocked to see another culture vanish into another variety of culture. Attempts have been made by scholars in field to supply some ready cogent explanations for this to rend but scholars like (Richardson and Boyd 2004) have drawn the conclusion that culture like other spicies will disappear over the broard Swath of human history

\subsection{Globalization and cultural universality: Toward McDonalization or Americcanization of society}

Convincing evidences have been provided in the leterature concerning the effect of globalization on cultural homogeneity. One such evidence stemmed from the concern whether globalization is eroding cultural differences and thereby promoting a universal global culture. In this regard (Ritzer 1996) made allusion that "more and more people throughout the world are Watching America films or accessing mail using hot mail account etc. Following this Ritzer in view state that this trend is causing distinctive, American culture to spread throughout the world. This principle that guides American fast food industry (Ritzer 1966) calls McDonalization of society following (Ritzer 1996) this principle is explained based on emphasis on quantity over quality, etc. His conclusion is that behavior is more affected by organization with which people interact than by their innate values. It is further stated that McDonalization is said to be evidence by diverse contact such as the way university courses are organized, the way people receive medical care or the way ceremonies are held. This trend alludes to social gerrymandering or brain washing.

On similar notes; Ogakwu (2013) stated in clear terms that globalization theatens cultural diversity and results in the loss of knowledge handed down over generation which in developing countries is of direct significance in sustainable use of natural resources. Adverse effects of globalization on cultural embeddedness have been attributed to such trend as the exploitation of indegerious people by foreign tourists' Accordingly it was reported that many native societies are being greatly exploited through tourism industry. That the interaction between western culture and indegenous one are often times lopsided. That the western tourists often view the nature group as quaint relics of the past that they can report back to their friends at home (Smith, 2000). That the tourist view themselves as superior and deserved to be served .

Another angle to the conflict between idegenous culture and the western communities is exploitations of the young adolescent by the foreign multinationals through consumerism (Renner 2017). 
This relates to the earlier idea of Ritzer (1996) on the perspectives of McDonalization society or universalization of western culture. A clear expression of this trend is viewed from the perspective of the young folks life styles in dressing language, nutrition or choice of food (fast food) hair styles, choice of music, choice of films, face book etc. This concept appeals categorically stated that this trend brings about erosion of cultural due to the sense of identity becoming more personal i.e individual choice rather than societal one. This is the true perspective of cultural disembeddedness. Inter and intra-community strife as well as family disintegration are clear results of this new orientation (Onyekwena, 2010)

Another area of collision between the two cultures is this dispossession of the local people of their traditional values (Maguey 1998) it was reported that many multinational cooperation buy or acquire lands from the local communities by a process of elite intervention thereby depriving them of their traditional land use and hence paushing them to the margins of the society, this trend is seen in resettlement schemes for communities where major development projects are under taken .

In view of the fore going many indigenous societies are apprehensive that this global pressure on their culture is leading to the erosion of their traditional values to the point that the diversity of culture in the world will be slowly whittled away to the point that there will be only one homogenous culture in the world.

\subsection{Globalization and cultural distinctiveness.}

Notwithstanding the loud outcry on the influence of globalization on cultural conflict there are forcible arguments in support of the positive influence of globalization on cultural identities.

Smith (2000) has put forward plausible able arguments on the role of global technology in promoting cultural chiotrictiveness. He said "the technological global Media can be empowering for various cultures as it allows self-representation and information sharing on a whole new level" further on that , "technology provides a medium where depiction of images and portrayals of self identify can provide the means by which truism can be established. Again, that global media centres allow culture a distinctive voice to promote awareness and provide public knowledge and understanding of their stories and identities voice (op cit). Additional that global technology has provided the opportunity to acquire collective identity along with identifying a place for distinctive culture.

Finally, that global social, political, and economic network will no doubt enable the prospect of empowering among cultural groups (smith 2000).

\subsection{Globalization ands information surface}

Information surface measures individuals and groups mental maps of the word. (Gould \& White, 1974). There is a corresponding ignorance surface which relates to inadequate information in the environment. Accordingly (Moghi 2007) has advocated that globalization has privileged and commercialized knowledge community as is a driving force for national and international political social and economics development .That when cultural arrangement provide input into the knowledge community, the demoniant culture will generally reveal in this scene. Smith (2000) believed that globalization began in the west and so that it is their ideas, ideologies, values and life style that are promoted and evangelized throughout the world. And again their thought and belief patterns are propagated throughout society enabling those who think alike while crushing those that do not (smith 2000). 


\subsection{Methodology of the study}

This study is a field survey design aimed at field data collection based on the methods of observation and field interview of respondents using questionnaire and other relevant instruments.

\subsection{Area of study}

The study area, Cross River State, is a geopolitical entity which form part of the 36 states of the National State, Nigeria. Ecologically, it falls within, two broad ecological biomes-the Northern Savanna biome and the Southern forest biome which extends up to the Guinea Coast of the Atlantic Ocean.

Culturally, it is heterogeneous by linguistic and ethnic composition. From the point of view of African Cosmology, there are several convergent norms and ethos among the disparate ethnic groups.

\subsection{Study population}

The entire population of study comprises all students of tertiary Institutions in the state. The categories of institutions included here are the Universities, Colleges of Education and the Polytechnics.

\subsection{Sampling procedure}

Multi stage procedure was adopted. First, cluster sampling was used based on the consideration of location of the institutions. Thus one institution was selected from each zone. Secondly, stratified sampling was employed based on selection according to class or level of schooling. The schools selected were Cross River State College of Education, Akamkpa, Nogak Polytechnic, Ikom and Cross River University of Technology, Okuku Campus, Yala.

Finally, purposive sampling was employed to select 200 students from each of the three clusters for the study.

\subsection{Instrument(s) for data collection}

The major instrument employed for data collection was the structured questionnaire for administration in the field for purposes eliciting responses by observation was also combined with method sporadically.

\subsection{Data collection procedure}

The first involved adoption of community penetration strategy whereby permission was formally sought from the head of the institution before proceeding on the field data capturing. The next stage involved field data, collection entry where questionnaires were administered and data was collected defacto.

\subsection{Data analysis}

Data was analysed usingthe chi-square technique

\section{Data presentation and analysis \\ Presentation:}

Field data was collected by interview method and presented in table I (male respondents) and table II (female respondents). The data were now tested statistically using the $x^{2}$ techniques as reflected in the analysis procedure that followed 
Table 1: Male students response rating.

\begin{tabular}{|l|l|r|r|r|c|}
\hline S/N & ITEM RESPONSE & \multicolumn{3}{|c|}{ RATING SCALES } \\
\cline { 3 - 5 } & CATEGORY & A & SA & DA & SDA \\
\hline 1. & African Spirit oneness & 64 & 32 & NIL & NIL \\
\hline 2. & Extended family system & 51 & 38 & 8 & 2 \\
\hline 3. & African traditional music & 46 & 43 & 3 & 3 \\
\hline 4. & Practice of sharing and caring & 47 & 44 & 3 & 1 \\
\hline 5. & Proficiency in use of language & 57 & 36 & 4 & 28 \\
\hline 6. & Preference of foreign language & 15 & 31 & 22 & 23 \\
\hline 7. & African food & 56 & 26 & 6 & 15 \\
\hline 8. & Practice of African traditional & 35 & 22 & 15 & 20 \\
\hline 9. & $\begin{array}{l}\text { Membership of traditional dance } \\
\text { pulp is instituting }\end{array}$ & 37 & 27 & 15 & \\
\hline 10. & Preference for native herism & 36 & 24 & 14 & \\
\hline
\end{tabular}

From the table above, 100 male students respondent were interviewed using the questionnaire as instruments for data collection based on a 4 point rating scale e.g. (A=Agree, SA=Strongly Agree, DA=Dis Agree, SDA= Strongly Disagree. The information elected were statistically tested using the $\mathrm{x}^{2}$ technique.

\section{Respondents rating by sex categorisation}

Table 2: Female students response rating.

\begin{tabular}{|c|l|l|l|l|l|l|}
\hline S/N & \multicolumn{1}{|c|}{ ITEM RESPONSE CATEGORY } & \multicolumn{5}{c|}{ RATING SCALES } \\
\cline { 3 - 6 } & & A & SA & DA & SDA & TOTAL \\
\hline 1. & African spirit of oneness & 51 & 39 & 3 & 2 & 95 \\
\hline 2. & Extended family system & 34 & 49 & 10 & 2 & 95 \\
\hline 3. & African traditional music & 34 & 51 & 8 & 2 & 95 \\
\hline 4. & Practice of sharing and caring & 42 & 53 & - & - & 95 \\
\hline 5. & Profiliency in the use of lang. & 37 & 50 & 8 & - & 90 \\
\hline 6. & Preference for foreign lang. & 12 & 17 & 20 & 46 & 95 \\
\hline 7. & African food or diet & 33 & 49 & 8 & 5 & 95 \\
\hline 8. & African traditional worship & 34 & 26 & 9 & 26 & 95 \\
\hline 9. & Membership of traditional dance & 25 & 32 & 20 & 18 & 95 \\
\hline 10. & Preference of native traditional Governance or leadership & 28 & 34 & 13 & 20 & 95 \\
\hline
\end{tabular}

From the table above, one hundred female students respondent were used in electing information for data collection on 4 points rating scale as above: $(\mathrm{A}=$ Agree, $\mathrm{SA}=$ Strongly Agree, $\mathrm{DA}=\mathrm{Dis}$ Agree, and SDA=Strongly Disagree.

\section{Data analysis}

Data was analysed using the technique for both hypothesis I and II which state as follows:

\section{Hypothesis I}

$\mathrm{H}_{\mathrm{O}}$ : There is no significant difference in the influence of globalization on male students cultural orientation in 
the study area

$\mathrm{H}_{\mathrm{I}}$ : There is a significant difference in the male influence of globalization on the male students cultural orientation in the area.

Table 3

Chi square table on Globalization impact on male student's cultural orientation on tertiary institutions

\begin{tabular}{|c|c|c|c|c|}
\hline$O_{i j j}$ & $E_{\mathrm{i} j}$ & $\left(O_{i j}-E_{i j}\right)$ & $\left(O_{i j}-E_{i j}\right)^{2}$ & $\frac{\left(O_{i j}-E_{i j}\right)^{2}}{E_{i j}}$ \\
\hline 64 & 44 & 20 & 400 & 9.090 \\
\hline 32 & 32 & 0 & 0 & 0.000 \\
\hline 0 & 9 & -9 & 81 & 9.000 \\
\hline 0 & 10 & -10 & 100 & 10.00 \\
\hline 51 & 46 & 5 & 25 & 0.543 \\
\hline 38 & 33 & 5 & 25 & 0.758 \\
\hline 8 & 9 & -1 & 1 & 0.111 \\
\hline 2 & 11 & -9 & 81 & 8.272 \\
\hline 46 & 44 & 2 & 4 & 0.091 \\
\hline 43 & 40 & 3 & 9 & 0.225 \\
\hline 3 & 9 & -6 & 36 & 4.000 \\
\hline 3 & 10 & -7 & 49 & 4.900 \\
\hline 47 & 45 & 2 & 4 & 0.088 \\
\hline 44 & 33 & 1 & 1 & 0.030 \\
\hline 3 & 9 & -6 & 36 & 4.000 \\
\hline 4 & 11 & -7 & 49 & 4.454 \\
\hline 57 & 45 & 12 & 144 & 3.273 \\
\hline 36 & 33 & 3 & 9 & 0.272 \\
\hline 4 & 9 & -5 & 25 & 2.778 \\
\hline 1 & 11 & -10 & 100 & 9.091 \\
\hline 15 & 44 & -29 & 841 & 19.113 \\
\hline 31 & 32 & -1 & 1 & 0.0313 \\
\hline 22 & 9 & 13 & 169 & 18.778 \\
\hline 28 & 10 & 18 & 324 & 32.400 \\
\hline 56 & 44 & 12 & 144 & 3.273 \\
\hline 26 & 40 & -14 & 196 & 4.900 \\
\hline 6 & 9 & -3 & 9 & 1.000 \\
\hline 7 & 10 & -3 & 9 & 0.900 \\
\hline 35 & 44 & -9 & 81 & 1.848 \\
\hline 22 & 40 & -18 & 324 & 8.100 \\
\hline 15 & 9 & 6 & 36 & 4.000 \\
\hline 23 & 10 & 13 & 169 & 16.900 \\
\hline
\end{tabular}




\begin{tabular}{lllll}
\hline 37 & 44 & -7 & 49 & 1.114 \\
27 & 40 & -13 & 169 & 4.225 \\
15 & 9 & 6 & 36 & 4.000 \\
16 & 10 & 6 & 36 & 3.600 \\
36 & 43 & -7 & 49 & 1.139 \\
24 & 32 & -10 & 100 & 3.125 \\
14 & 9 & 5 & 25 & 2.778 \\
20 & 10 & 10 & 100 & 10.000 \\
Total & & & & $\mathbf{2 1 2 . 2 0 0 3}$ \\
\hline
\end{tabular}

\section{Decision rule:}

The degree of freedom $(\mathrm{R}-1)(\mathrm{C}-1)=(10-1),(4-1)=(9,3)$ At $\alpha=0.05$ level of significant and degree of freedom 9,3. A table value of $\chi^{2}(0.05,4,3)=3.33$, and 0.352 , if the computed $\chi^{2}$ is $>$ the table $\chi^{2}$ we reject the null hypothesis or otherwise if $\chi^{2}>3.33$ or $\chi^{2},<0.532$

\section{Hypothesis I}

$\mathrm{H}_{\mathrm{O}}$ : There is no significant difference in the influence of globalization on female students cultural orientation in the study area

$\mathrm{H}_{\mathrm{I}}$ : there is a significant difference in the female influence of globalization on the male students cultural orientation in the area.

Table 4

Chi square table on Globalization impact on female student's cultural orientation on tertiary institutions

\begin{tabular}{lllll}
\hline$O_{i j}$ & $E_{i j}$ & $\left(O_{i j}-E_{i j}\right)$ & $\left(O_{i j}-E_{i j}\right)^{2}$ & $\frac{\left(O_{i j}-E_{i j j}\right)^{2}}{E_{i j}}$ \\
\hline 51 & 33 & 18 & 324 & 9.818 \\
39 & 40 & -1 & 1 & 0.025 \\
3 & 10 & -7 & 1 & 4.900 \\
2 & 12 & -10 & 49 & 8.333 \\
34 & 33 & 1 & 1 & 0.030 \\
49 & 40 & 9 & 81 & 2.025 \\
10 & 10 & 0 & 0 & 0.000 \\
2 & 12 & -10 & 100 & 8.333 \\
34 & 33 & 1 & 1 & 0.030 \\
51 & 40 & 9 & 81 & 2.025 \\
8 & 10 & -2 & 4 & 0.400 \\
2 & 12 & -10 & 100 & 8.333 \\
42 & 33 & 9 & 81 & 2.454 \\
53 & 40 & 13 & 169 & 4.225 \\
0 & 10 & -10 & 100 & 10.000 \\
0 & 12 & -12 & 144 & 12.000 \\
37 & 33 & 4 & 16 & 0.485 \\
\hline
\end{tabular}




\begin{tabular}{lllll}
\hline 50 & 40 & 10 & 100 & 2.500 \\
8 & 10 & -2 & 4 & 2.500 \\
0 & 12 & -12 & 144 & 12.40 \\
12 & 33 & -21 & 441 & 13.363 \\
17 & 40 & -23 & 529 & 13.225 \\
20 & 10 & 10 & 100 & 10.00 \\
46 & 12 & 34 & 1156 & 96.333 \\
33 & 33 & 0 & 0 & 0 \\
49 & 40 & 9 & 81 & 3.075 \\
8 & 10 & -2 & 4 & 0.500 \\
5 & 12 & -7 & 49 & 4.0833 \\
34 & 33 & 1 & 1 & 0.0308 \\
26 & 40 & -14 & 196 & 4.900 \\
9 & 10 & -1 & 1 & 0.100 \\
26 & 12 & 14 & 196 & 16.333 \\
25 & 33 & -8 & 64 & 1.939 \\
32 & 40 & -8 & 64 & 1.600 \\
20 & 10 & 10 & 100 & 10.00 \\
18 & 12 & 6 & 36 & 3.000 \\
28 & 33 & -5 & 25 & 0.757 \\
34 & 40 & 6 & 36 & 0.900 \\
13 & 10 & 7 & 49 & 4.900 \\
20 & 12 & 8 & 64 & 5.333 \\
$x^{2}$ & & & & $\mathbf{2 8 1 . 1 8 8 1}$ \\
\hline
\end{tabular}

\section{Decision rule:}

The degree of freedom (R-1) $(\mathrm{C}-1)=(10-1),(4-1)=(9,3)$ At $\alpha=0.05$ level of significant and degree of freedom 9,3. A table value of $\chi 2(0.05,4,3)=3.33$, and 0.352 , if the computed $\chi^{2}$ is $>$ the table $\chi^{2}$ we reject the null hypothesis or otherwise if $\chi^{2}>3.33$ or $\chi^{2},<0.532$

\section{Discussion of findings}

The results of the hypothesis tested portrayed a variegated mode of perception of the value of the alien culture by the students. Within the in group assessment there is significant disparity in the perceptual modes by the individual subjects. This implies that there is no convergent mode of receptivity of what characterise the new culture (western culture). This development agrees with the notion put forward by Appelbcum and Robinson (2000) in their view that "globalization is the process of reshaping how we traditionally go about studying the social world and human culture" this explanation goes on to support the basic tennet of milliue culture which reflects" what Butiner (1995) calls "individual geographies" individual geographies is predicated on the notion of "ecological isotope" which was on ingrained preference for native life forms. This means that some people based on their cultural inprint are quite resilient to change. The impact differences is 
differences as suggest by the alludes to the position held by the United Nations Poverty and Development Division that globalization is increasing interaction across national boundaries that affect many aspect of life individual education, economics, social life culture and polices" this simply implies that the impact place and people determined. Predicated on the multidimensional influence individual will of necessity by attracted to one or two aspects to the neglect of many others. This is conception is clearly by epitomized certain aspects of the life modes of these individual as seen by their dressing codes Hair to, language, music preference and overall social orientation.

The gross assessment of their life modes is one of tendency towards their native cultural imprint infavour of the foreign western culture. Hence Boyd and Richardson(1994) spoke of Munduruuni society if Brazil as "hunrrying to their cultural demise " and blamed" the technology of the industrial world for the unlimited destruction of their culture". The expression such as above addresses directly the true essence if the new orientation of youths in the Tertiary institutions and even beyond. In essence, the impact of technology on the world societal life modes is beyond explianation. Form the educational parlence, technology has caused significant wanning of interest of our students in the culture of reading fece book has have taken over the place of real books, libraries are rarely visited due to the appearance of initial. The overall sense if humanities is fast disappearing and giving way to brutality and agreesive instincts caused by the choice of films watched and the categories of companies kept. Technology and western cultural exploration has led to the production of a universal global culture where western culture has predated or dominated the native culture of the developing world regions. This Brend led Ritzer(1996) to introduce the phrase MacDonalization of society or what is otherewise called Americanization of the society.

This view represents the trend that characteristic how American culture is exported to every part of the world.

In its clear expression, it seen in the choice of food, preference of youths for "fast food and other foreign dishes to the native dish, music preference by them, loss of sense of communication and the chioce of individualism and so on. Ritzer's (1996) concept of globalization is extended to other facets of societal life as in the way university lecturers are designed and taught, how ceremonies are organized and the entire gamut of life forms.

The current orientation of most students of tertiary institutions in the study area (Cross River State) contains or support Ritzer (1996) advocacy that behaviour is mostly affected by organization with which peole interact than by imate value.

The perspective of cultural anomic or cultural loss has strongly been alluded to by scholars in the field of cultural anthropology. In the sense Ogakwu (2013) stated in clear terms that "globalization threatens cultural diversity and has resulted in the loss essence of knowledge handed over generation and which in developing countries is of direct significance to sustainable development. This allusion foredicates on the essense of indigenous system of the local traditional societies which have grieviously been eroded by contact, with western culture (globalization).

Before the comergence of western knowledge system, local ingeniuty lead fosterred development and societal progress in different traditional societies but global cultural attraction has led to the annihilation or disemddness of most local cultural values.

One visible aspect of this traditional cultural extinction derives from the spirit of individualism or independence that characterise behavioural orientation of most youths/students in our Tertiary Institution. This tendency has grievious backlash on communual livelihood, peace and harmony in the institutions of learning, family life sustainability and general societal progress. This new orientation has manifested in 
frequent and sporadic incidents of strite and objectification in the schools, families and the general public. Correspondingly, this leads to lowering productivity in learning.

A poignant dimension of this new culture is the emmerging trend of truancy and lecture boycorts by both make and female students.

However, in some circles there are strong arguments in support the are role of global culture and global technology in promoting " cultural distinctiveness among cultural groups.

In the sense, Smith(2000) has provided plausible arguments in support of how the new global technology can embance or encourage the promotion of cultural identiifties. He was able to forcibly substantiate how the technlogical global media can be empowering for various cultures as it allows self representation, information sharing and depiction of images.

Again, the divergent responses of the research subjects regarding their adoption and perception of the new global culture is a function of their disparate information surface. The notion of imformation surface" and it's opposite expression, "ignorance surface" were the original ideals of Gould and while(1974) in their works on mental maps" which tends to explain the degree of individual perception of the knowledge of places, phenomena or situations on the earth surface. Inoformation surface broadens individual perception of events or situation while their ignorance surface" narrows it. Thus the divergent respeonses of the respondents may possibly be products of limited or enhanced information surface by the respondents, otherwise a good majority possess enhanced preference for the new globalized culture.

On the issue of general explanations on cultural loss some experts in social anthropology are of the view that "culture like speciies population can disappear over the broad Swath of human history.

\section{Conclusion}

Societal changes or evolution have progressed apace over the cause of human existence on earth. Overtime people have continously desired to understand what lies beyond the distant horizon. This curiosity spurred the desire for exploration and expedition that led to the discovery of unknown teritories. Global Interdependence and global interconnectivity began quite early and has gradually gathered momentum after the Industrial Revolution and the two world wars which have eventually culminate in the present stage global integration. Cultural coalescence or attrition have both positive and negative sides but the major concern is the process of domination of one culture by the other. Obviously, the current lamentation borders on the collosal swallowing of other cultures by the westerns culture of American and European. MacDonalization or Americanization as Ritzer(1996) coined it has led to the suffocation of other cultures leadning to native life styles disembddedness or lack of interest. Our advocacy in this study is that concerted effeorts, be made by education planners, curriculum designers, schools policy implementors and other stake holders in our educational planner to attempt what skinner will call " enviornmental filtering (Gould and White 1974) which involves careful selection of the relevante experiences in the teaching and learning process. 


\section{References}

Anih, S.E, 2007. Authentic Education for Nigeria in the $21^{\text {st }}$ Millenum Enugu, Fouth Dimension Publishers. Boyd and Richerson, K. 1991. Culture, seeder Trend: Modernization and culture Loss. International Journal of Anthropology (2) 1.245-261.

Gould, P White, R. 1994. Mental Maps, London, Penguin Publications.

Harner, 2001. Cultural Studies: The Black well Encyclopedia of Sociology, Oxford ,Blackwell Publishing.

Harrison, 2001 . Journal of Ethnography and Cultural Diffusion (3) 4. 20-51

Maguey, I.S. 1998. Modernization and Cultural in Latin America. Journal of Social Anthropology(5) 7, 3548.

Mohai B.N. 2007. Impact of Globalization on Behavioural Charge in Developing Nations. In Sleater R. (Ed) London Prenthrills

Murphy, I. .2001. Reclaiming Scientific Anthropology in Ogakwu and Isife (2013) Globalization and Education for Sustainable Development in Nigeria. In Globalization and Education in Nigeria,

Oneykwena, F.C. 2010. Impact of Globalization on Cultural Diversity in Developing Nations. In Ejoirgu E(Ed) Globalization and Education for Sustainable Development in Nigeria.

Oxford Advanced Learner Dictionary (2000) $6^{\text {th }}$ Edition.

Renner, B.N. 2017. A Global Economy: Modernity and the Future world. Cambridge, University press.

Ritzer, 1996. The Machonization of society in Ronderialli D.A and Heffron J.M. (Ed), Colorado, Lynne, Reinner Publishers.

Siskind, I.L. 2005. Ethno Ecology: The Latin American Aborigins and Change. A Seminar Presentation.A Treatise on Anthropology.

Smith K.E. 2000. "Globalization and is Effects on Cultural Diversity". Journal of Cultural Diffusion in Africa, 10, 62-67.

The United Nations Poverty and Development Division (1996). In Dr. International (2000) institute of German Dev. Coop.

UNESCO 2011. “The Universal Declaration on Cultural Diversity” In Ogakwu and Isife 2013. Globalization and Education for sustainable Development, Seminal presentation..

Watson B.K. .2005. Chimas Big Macdonalization. Foreign affairs 79, 120-131

World Bank 2006. World forum on cultural Diversity and sustainable development implications of Globalization.

Appelbaum, R.E. and Robinson, W.I. 2005. Critical Globalization Studies: New York, Routledge. 